Contemporary Issues in Toxicology

\title{
Signal transduction profile of chemical sensitisers in dendritic cells: An endpoint to be included in a cell-based in vitro alternative approach to hazard identification?
}

\author{
Bruno Miguel Neves ${ }^{\mathrm{a}, \mathrm{b}}$, Margarida Gonçalo ${ }^{\mathrm{c}}$, Américo Figueiredo ${ }^{c}$, Carlos B. Duarte ${ }^{\mathrm{b}, \mathrm{d}}$, \\ Maria Celeste Lopes ${ }^{\mathrm{a}, \mathrm{b}}$, Maria Teresa Cruz ${ }^{\mathrm{a}, \mathrm{b}, *}$ \\ a Faculdade de Farmácia, Universidade de Coimbra, Coimbra 3000-548, Portugal \\ b Centro de Neurociências e Biologia Celular, Universidade de Coimbra, Coimbra 3004-517, Portugal \\ c Faculdade de Medicina (Serviço de Dermatologia), Hospital da Universidade de Coimbra, Coimbra 3000-075, Portugal \\ d Centro de Neurociências e Biologia Celular and Departamento de Ciências da Vida, Universidade de Coimbra, 3004-517 Coimbra, Portugal
}

\section{A R T I C L E I N F O}

\section{Article history:}

Received 26 July 2010

Revised 28 September 2010

Accepted 6 October 2010

Available online 13 October 2010

\section{Keywords:}

In vitro sensitisation test

Dendritic cells

Signal transduction

Sensitiser

Irritant

\begin{abstract}
A B S T R A C T
The development of non-animal testing methods for the assessment of skin sensitisation potential is an urgent challenge within the framework of existing and forthcoming legislation. Efforts have been made to replace current animal tests, but so far no alternative methods have been developed. It is widely recognised that alternatives to animal testing cannot be accomplished with a single approach, but rather will require the integration of results obtained from different in vitro and in silico assays. The argument subjacent to the development of in vitro dendritic cell (DC)-based assays is that sensitiser-induced changes in the DC phenotype can be differentiated from those induced by irritants. This assumption is derived from the unique capacity of DC to convert environmental signals encountered at the skin into a receptor expression pattern (MHC class II molecules, co-stimulatory molecules, chemokine receptors) and a soluble mediator release profile that will stimulate $\mathrm{T}$ lymphocytes. Since signal transduction cascades precede changes in surface marker expression and cytokine/ chemokine secretion, these phenotypic modifications are a consequence of a signal transduction profile that is specifically triggered by sensitisers and not by irritants. A limited number of studies have addressed this subject and the present review attempts to summarise and highlight all of the signalling pathways modulated by skin sensitisers and irritants. Furthermore, we conclude this review by focusing on the most promising strategies suitable for inclusion into a cell-based in vitro alternative approach to hazard identification.
\end{abstract}

(c) 2010 Elsevier Inc. All rights reserved.

\section{Contents}

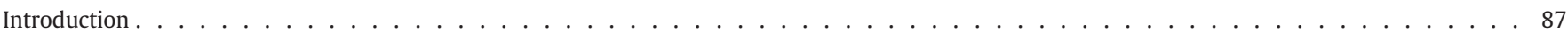

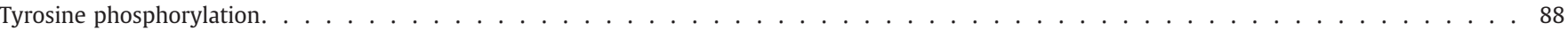

Activation of protein kinase $\mathrm{C}(\mathrm{PKC}) \ldots \ldots \ldots \ldots \ldots$

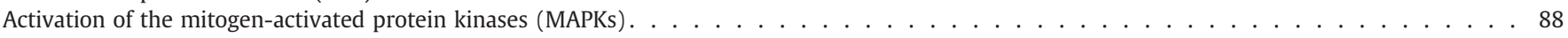

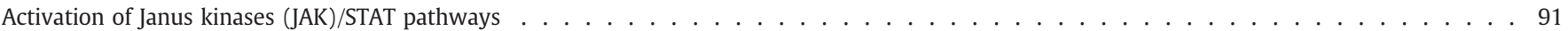

Intracellular redox imbalance, changes in cell surface thiols and glutathione depletion . . . . . . . . . . . . . . . . . . . . . . 92

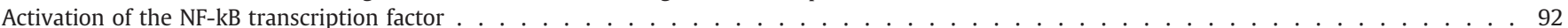

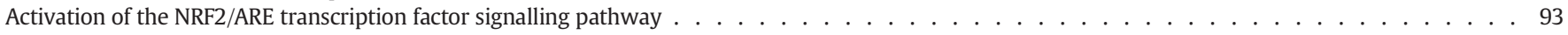

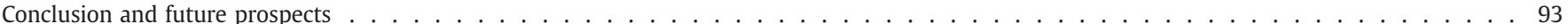

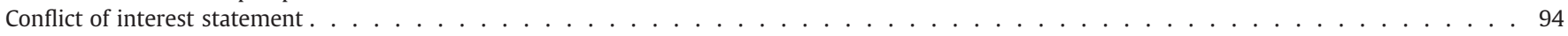

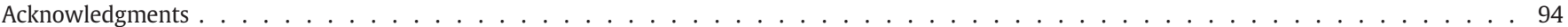

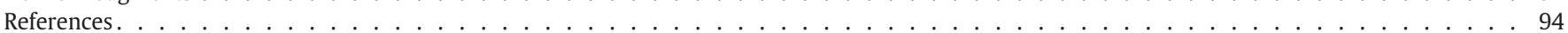

\section{Introduction}

* Corresponding author. Faculdade de Farmácia, Pólo das Ciências da Saúde, Universidade de Coimbra, 3000-548 Coimbra, Portugal. Fax: + 351239480217.

E-mail address: trosete@ff.uc.pt (M.T. Cruz).
Allergic contact dermatitis (ACD) is one of the most common occupational diseases in developed countries and 19.5\% of the general population is sensitive to at least one allergen (Thyssen et al., 2007). ACD is 
the clinical condition caused by an allergic immune response following skin exposure to a large subset of small reactive chemicals (haptens) that can be found in the environment and in many household products. A large number of these chemicals are electrophilic molecules (with the exception of metals and thiols) that have the ability to bind skin proteins and form sensitising complexes. Several in vivo methods have been proven accurate in predicting chemicals that possess skin sensitising properties, such as the local lymph node assay (Basketter et al., 2002). However, the skin sensitisation potential is an endpoint that needs to be assessed within the framework of existing and forthcoming legislation, namely the 7th Amendment to the Cosmetic Directive (Directive 2003/15/ EC) (EU, 2003) and more recently the new European Cosmetic Regulation (on November, 2009) (EC, 2009) that seek to gradually eliminate animal experiments from the safety and toxicity testing of cosmetic ingredients and other chemical substances. The final cut-off date is March 2013, when cosmetic products containing an ingredient whose safety was tested in animals will not be allowed for sale in Europe, irrespective of the availability of alternative non-animal tests. Therefore, the rapid development and validation of in vitro testing strategies is a prerequisite to maintain Europe's competitiveness in the cosmetic industry. Progress in understanding the mechanisms of skin sensitisation and its effects on the production of cytokines/chemokines by different skin cell types provides the opportunity to develop in vitro tests as an alternative to in vivo sensitisation testing. Currently, the most promising alternative in vitro approaches are based on Langerhans (LC)/dendritic cells (DC) systems, given the pivotal role played by these cells in ACD (Ryan et al., 2007). Since LC are a relatively minor population in the epidermis ( 2 to $5 \%$ ), several cell culture protocols have been developed to derive LC-like dendritic cells, namely, DC derived from CD $34^{+}$progenitors from cord blood, DC derived from blood monocytes and monocytic cell lines with the capacity to develop into DC, such as THP-1, U-937 and MUTZ-3. In the studies that use these DC cell models, the activation of endocytosis, the increase in phosphotyrosine levels, the up-regulation of cell surface markers and the increase in cytokine and chemokine production were analysed as markers for the sensitisation capacity (dos Santos et al., 2009). In this context, our work has been performed using a mouse skin-derived dendritic cell line, FSDC, that is a model of immature DC, with morphological, phenotypical and functional characteristics of Langerhans cells (Girolomoni et al., 1995). In contrast to other DC lines used for studying skin sensitisation hazards, FSDC have the advantage of being cultured in the absence of exogenous recombinant growth factors. We observed that the sensitisers, 2,4-dinitrofluorobenzene (DNFB) and nickel, increased the expression of the membrane-associated proteins CD40 and interleukin (IL) 12 receptor, whereas the non/very weak skin sensitiser 2,4-dichloronitrobenzene (DCNB) did not affect the expression of either protein (Vital et al., 2004; Matos et al., 2005a). Recently, we also found that the CXCR4 chemokine receptor is selectively modulated by skin sensitisers (and not by irritants) in FSDC (Neves et al., 2008).

An extremely important, yet sometimes neglected, fact is that all DC modifications triggered by skin sensitisers, both at the genomic and proteomic levels, result from the coordination of different intracellular signalling pathways that are specifically triggered by skin sensitisers and not by irritants. Accordingly, the recently formulated paradigm "Toxicity testing in the 21st century: A Vision and a Strategy" (National Research Council, 2007) focuses on the specific toxicity pathways linked to these endpoints rather than specific cellular markers. We and other authors showed that contact sensitisers activate the mitogen-activated protein kinases (MAPKs), mainly the p38 MAPK (Matos et al., 2005a,b; Koeper et al., 2007; Trompezinski et al., 2008). Moreover, we and other authors have shown that further downstream signals elicited by skin sensitisers include the activation of the transcription factors nuclear factor kappa-B (NF-kB) and activating protein-1 (AP-1) (Cruz et al., 2002, 2004; Ade et al., 2007; Antonios et al., 2009). The following question remains: whether all contact sensitisers use the same signal transduction pathways as the stimuli known to induce DC maturation, such as lipopolysaccharide, proinflammatory cytokines, or CD40 ligand, or whether there is an innate cellular signalling pathway profile activated only by skin sensitisers. A related question is whether contact sensitisers can be classified on the basis of their signal transduction profiles and if this profile can be used to distinguish skin sensitisers from nonspecific chemical irritants. There is a gap in this issue, since few studies have addressed the impact of skin sensitisers and irritants on the signal transduction profile of skin cells, namely dendritic cells and keratinocytes. Additional studies are required to understand which signalling pathways function as sensors for skin sensitisers and are responsible for the phenotypic and functional modifications of dendritic cells that initiate the early events in the development of ACD. The focus of this review is to summarise the current status of the intracellular signalling pathways that are activated in DC or DC-like cells upon exposure to skin sensitisers and irritants.

\section{Tyrosine phosphorylation}

The work of Kuhn et al., (1998) was pioneering in the detection of tyrosine phosphorylation induced by contact sensitisers in human MHC class II-positive antigen-presenting cells. The authors used different cell types, namely human LC, immature fresh DC isolated from the blood, monocytes, B cells and HLA-DR ${ }^{\text {negative }}$ cells along with several chemicals, including strong sensitisers (DNFB, 5-chloro-2-methylisothiazolinone plus 2-methylisothiazolinone, ( $\mathrm{MCI} / \mathrm{MI})$, thimerosal and formaldehyde), weak sensitisers (methyl paraben, 2-phenoxyethanol) and the irritants SDS and BC. Contact sensitisers increased tyrosine phosphorylation exclusively in MHC class II-positive antigen-presenting cells. Furthermore, only the strong sensitisers induced tyrosine phosphorylation in human blood-derived dendritic cells. In contrast, the weak sensitiser phenoxyethanol and the irritants SDS and BC failed to modulate tyrosine phosphorylation. This work was confirmed in murine LC and a significant increase in tyrosine phosphorylation was observed in response to the strong sensitisers 2,4,6-trinitro-chlorobenzene (TNCB) and MCI/MI, but not after cell treatment with the irritants SDS and benzoic acid (Neisius et al., 1999).

Although we can conclude from these studies that the activation of cellular tyrosine kinases cannot be used to distinguish sensitisers from irritants, because the weak sensitisers tested did not increase tyrosine phosphorylation, this assay could potentially be useful to detect strong and extreme allergens.

\section{Activation of protein kinase C (PKC)}

The involvement of PKC on LC migration from the epidermis was first demonstrated by the work of Halliday and Lucas (1993). The authors observed that the topical application of an analogue of diacylglycerol, the physiological activator of PKC, reduced the density of epidermal LC after $24 \mathrm{~h}$ using both BALB/c and C57BL mice. Additionally, LC migration from the epidermis, induced by the contact sensitiser TNCB, was blocked when PKC was inhibited by palmitoyl-DL-carnitine chloride or D-sphingosine, indicating that LC cannot migrate from the epidermis when PKC is inhibited. More recently, the work of Staquet et al. (2004) addressed the migratory capacity of epidermal and in vitro-generated LC. They observed that, in the presence of PKC inhibitors, Bandrowski's base- or 2 , 4-dinitrobenzenesulfonic acid-induced LC migration was strongly decreased.

Because LC migration is a prerequisite for skin sensitisation, it would be interesting to evaluate the direct effect of skin sensitisers and irritants on PKC activation in dendritic cells, which was not addressed until now.

\section{Activation of the mitogen-activated protein kinases (MAPKs)}

Different signalling pathways such as MAPKs and NF-kB play important roles in DC maturation (Rescigno et al., 1998; Arrighi et al., 
2001; Aiba et al., 2003; Boisleve et al., 2005; Neves et al., 2009). The MAPKs p38 MAPK and extracellular signal-regulated kinases 1/2 (ERK1/2) are involved in a wide variety of cellular responses, including proliferation, differentiation and apoptosis. The ERK1/2 pathway is most commonly linked to the regulation of cell differentiation and survival, whereas JNK and p38 MAPK pathways, usually referred to as stress-stimulated MAPKs, are activated by various environmental stresses such as osmotic shock, UV radiation, heat shock, oxidants and proinflammatory cytokines and are also known to mediate apoptosis.

Arrighi et al. (2001) reported, for the first time, that DC maturation (observed as the up-regulation of CD80, CD86 and CD83) induced by the contact sensitisers DNFB and nickel, was dependent upon p38 MAPK phosphorylation and was inhibited by SB203580, a specific p38 MAPK inhibitor. The irritants SDS and BC did not trigger p38 MAPK phosphorylation. The results showed that p38 phosphorylation in DC may be useful for the identification of potential skin contact sensitisers. The activation of p38 MAPK and ERK1/2 was also induced by the sensitiser TNCB in DC (Bruchhausen et al., 2003) and MAPKs activation by contact sensitisers was later confirmed (Aiba et al., 2003). The authors stimulated human monocyte-derived dendritic cells with nickel and DNCB and observed that DNCB-induced p38 MAPK and JNK1/2 phosphorylation, whereas nickel-induced p38 MAPK, JNK1/2 and ERK1/2 phosphorylation. In contrast, the irritants BC and SDS did not activate these signal transduction pathways. By using specific inhibitors for ERK and p38 MAPKs pathways, PD98059 and SB203580, respectively, the authors demonstrated that the DNCB-induced up-regulation of CD86, HLA-DR, CD83 and IL-8 and the nickel-induced increase of CD83 and IL-12 p40 were mediated by the p38 MAPK pathway, whereas the ERK pathway modulated the production of IL- $1 \beta$ and tumour necrosis factor (TNF)- $\alpha$ in nickel treated-cells. The results showed that both sensitisers stimulated different signal transduction pathways and subsequently induced different phenotypic and functional changes in DC. Accordingly, Iijima et al. (2003) demonstrated that TNF- $\alpha$ and DNCB activate the p38 MAPK pathway at early and late phases, respectively and thereby induce murine DC maturation through different signalling pathways. The Pallardy group subsequently confirmed the activation of p38 MAPK by metallic haptens in dendritic cells (Ade et al., 2007; Antonios et al., 2009); the authors reported that $\mathrm{NiSO}_{4}$ and $\mathrm{CoCl}_{2}$, but not $\mathrm{K}_{2} \mathrm{Cr}_{2} \mathrm{O}_{7}$, activated the MAPKs pathways and the NF-kB transcription factor. In this work, p38 MAPK activation regulated the $\mathrm{NiSO}_{4}$-induced CD86 and CD83 expression while it only affected the $\mathrm{CoCl}_{2}$-induced CD83 expression. Moreover, the authors also reported that IL-6 production induced by $\mathrm{NiSO}_{4}$ and $\mathrm{CoCl}_{2}$ strongly depended on all MAPKs, while NiSO4-induced IL-12p40 synthesis was only dependent on p38 MAPK and JNK pathways. The results showed that both $\mathrm{NiSO}_{4}$ and $\mathrm{CoCl}_{2}$ activate similar signalling pathways that play different roles in DC maturation, depending on the hapten used. Recent studies also showed that p38 MAPK is activated by $\mathrm{NiSO}_{4}$ in human monocytederived DC and cooperates for IL-12 production (Antonios et al., 2010). In human $\mathrm{CD} 34^{+}$-derived DC, nickel activates p38 MAPK, ERK1/2 and JNK, all of which are MAPKs involved in the expression of CD83, CD86 and CCR7 but not in the nickel-induced down-regulation of E-cadherin and Langerin (Boisleve et al., 2005). TNF- $\alpha$ production induced by DNCB was also linked to the activation of p38 MAPK and JNK (Boisleve et al., 2004). In previous results performed with the foetal skin-derived dendritic cell line (FSDC), we reported that DNFB activates p38 MAPK and ERK1/2 via the production of reactive oxygen species and that protein oxidation plays an important role in MAPKs activation (Matos et al., 2005b). These results are in agreement with the key role of oxidative stress in the activation of MAPKs (Mizuashi et al., 2005; Hirota et al., 2009; Suzuki et al., 2009; Kagatani et al., 2010).

The early intracellular mechanisms involved in DC maturation were also addressed in other studies (Trompezinski et al., 2008). The authors investigated whether MAPKs were induced by sensitisers (nickel, DNCB or thimerosal) and the irritant SDS. They observed that
SDS did not induce changes in signalling pathways, whereas nickel, DNCB and thimerosal markedly activated p38 MAPK and JNK. In contrast, ERK1/2 phosphorylation was completely inhibited by DNCB or thimerosal but only activated by nickel. Pre-treatment with the p38 MAPK inhibitor SB203580 suppressed the ERK1/2 inhibition induced by DNCB or thimerosal, suggesting a direct interaction between p38 MAPK and ERK1/2 pathways.

The study of the activation of MAPKs by skin sensitisers was also extended to other cell models, namely to skin explants and to the THP-1 monocytic cell line. Therefore, murine and human skin explants, as well as reconstituted skin models (epidermal model EST-1000 and full-thickness model AST-2000), were exposed to sensitising (oxazolone and DNFB) or irritant (SDS and TritonX-100) compounds and MAPKs (p38, ERK1/2 and JNK1/2) phosphorylation, signal transducer and activator of transcription (STAT) 1 and phospholipase C (PLC)- $\gamma$ were evaluated (Koeper et al., 2007). In skin explants, all three MAPKs were selectively activated after exposure to sensitising compounds. For the reconstituted skin models, p38 MAPK and JNK1/2 phosphorylation was stimulated by allergens, whereas ERK1/2 activation was induced by treatment with irritants; the activation of PLC $\gamma$ and STAT1 were never detected. In two recent papers, the authors addressed MAPKs activation induced by chemicals in the THP-1 human monocytic cell line (Miyazawa et al., 2008; Nukada et al., 2008) and the authors found that DNCB and nickel-induced p38 MAPK and ERK phosphorylation. The inhibition of p38 MAPK activation selectively blocked DNCB-induced TNF- $\alpha$ release, but not nickel-induced release. In contrast, inhibition of the ERK pathway selectively suppressed nickel-induced TNF- $\alpha$ release but not DNCB-induced release. In addition, the authors found that the inhibition of the 38 MAPK and ERK pathways caused a selective down-regulation of CD86, CD54 and/or CD40 expressions. In particular, inhibition of p38 MAPK suppressed DNCBinduced CD86, CD54 and CD40 expressions and nickel-induced CD86 expression, while inhibition of the ERK pathway suppressed CD86, CD54 and CD40 expressions induced by both allergens (Miyazawa et al., 2008). The authors extended their work to include the chemokine IL-8 and observed that the inhibition of ERK suppressed the DCNB- and nickelinduced production of this interleukin, whereas the inhibition of p38 MAPK only suppressed the IL- 8 production induced by DNCB (Nukada et al., 2008). The results showed that both DNCB and nickel activate p38 MAPK and ERK in THP-1 cells and thereby stimulate phenotypic changes through the different signal transduction pathways. Accordingly, Megherbi and colleagues reported that DNFB activated p38 MAPK in the THP-1 cell line, which is the signalling pathway responsible for the observed changes in CD54 expression and IL-8 release (Megherbi et al., 2009). The chemical-induced activation of MAPKs in THP-1 was further confirmed by Mitjans et al. (2008), who exposed THP-1 cells to contact allergens (cinnamaldehyde, DNCB, nickel, penicillin G, p-phenylenediamine and tetramethylthiuram disulfide) to respiratory allergens (ammonium hexachloroplatinate, diphenylmethane diisocyanate and trimellitic anhydride) and to irritants (salicylic acid, phenol and SDS) and investigated if a common activation pathway in allergen-induced IL-8 production could be identified. They demonstrated that all chemical allergens tested activated p38 MAPK and using its selective inhibitor SB203580, a significant modulation of induced IL-8 release was observed in all cases. The results showed that the activation of p38 MAPK represents a common pathway triggered by allergens (Mitjans et al., 2008). Recently, the same group extended these observations and conclusions to a new panel of sensitisers ( $p$-benzoquinone, 2-aminophenol, isoeugenol, diethyl maleate, citral and imidazolidinyl urea) and proposed the use of IL-8 release and p38 MAPK activation in THP-1 cells to identify allergens and assess their potency in vitro (Mitjans et al., 2010).

Taken together, all of these data indicate that chemical sensitisers differentially modulate MAPKs signalling pathways and p38 MAPK seems to be the most promising signalling pathway for inclusion in a potential in vitro test for skin sensitisation hazards. Accordingly, we also observed in the FSDC cell line that p38 MAPK is a specific sensor for skin sensitisers, because all of the sensitisers tested (nickel, 
Table 1

Intracellular signalling pathways modulated by chemicals in DC or DC-like cells and its phenotypic/functional modifications.

\begin{tabular}{|c|c|c|c|c|}
\hline Signalling pathway & Chemical & $\begin{array}{l}\text { Type of } \\
\text { modulation }\end{array}$ & Phenotypic modification & References \\
\hline \multirow[t]{8}{*}{ JAK/STAT } & Sensitisers & & & \multirow{8}{*}{$\begin{array}{l}\text { Antonios et al. (2010), Valk et al. (2002), } \\
\text { Koeper et al. (2007) }\end{array}$} \\
\hline & $\mathrm{MCI} / \mathrm{MI}$ & No activation & & \\
\hline & Thimerosal & No activation & & \\
\hline & TNCB & No activation & & \\
\hline & Formaldehyde & No activation & & \\
\hline & Oxazolone & No activation & & \\
\hline & DNFB & No activation & & \\
\hline & Nickel & Activation & IL-12 production & \\
\hline \multirow[t]{4}{*}{ PKC } & Sensitisers & & & \multirow[t]{4}{*}{ Staquet et al. (2004), Halliday and Lucas (1993) } \\
\hline & TNCB & Not determined & LC migration & \\
\hline & DNBS & & & \\
\hline & Brandrowski's base & & & \\
\hline \multirow[t]{12}{*}{ Tyrosine phosphorylation } & Strong sensitisers & & & \multirow[t]{12}{*}{ Kuhn et al. (1998), Neisius et al. (1999) } \\
\hline & DNFB & Activation & & \\
\hline & $\mathrm{MCI} / \mathrm{MI}$ & Activation & & \\
\hline & Thimerosal & Activation & \multirow[t]{9}{*}{ Not determined } & \\
\hline & Formaldehyde & Activation & & \\
\hline & TNCB & Activation & & \\
\hline & Weak sensitisers & & & \\
\hline & $\begin{array}{l}\text { Phenoxyethanol } \\
\text { Irritants }\end{array}$ & No modulation & & \\
\hline & $\begin{array}{l}\text { Benzalkonium } \\
\text { chloride }\end{array}$ & No modulation & & \\
\hline & SDS & No modulation & & \\
\hline & SLS & No modulation & & \\
\hline & Benzoic acid & No modulation & & \\
\hline \multirow[t]{9}{*}{ NF-kB } & Sensitisers & & \multirow{9}{*}{$\begin{array}{l}\text { Up-regulation of CD } 40, \text { HLA-DR and } \\
\text { cytokine expression }\end{array}$} & \multirow{9}{*}{$\begin{array}{l}\text { Ade et al. (2007), Aiba et al. (2003), } \\
\text { Antonios et al. (2009, 2010), } \\
\text { Cruz et al. (2002, 2004) }\end{array}$} \\
\hline & Nickel & Activation & & \\
\hline & DNFB & Activation & & \\
\hline & $\mathrm{COCl}_{2}$ & Activation & & \\
\hline & $\mathrm{K}_{2} \mathrm{Cr}_{2} \mathrm{O}_{7}$ & No activation & & \\
\hline & DNCB & No activation & & \\
\hline & Irritants & & & \\
\hline & SLS & No activation & & \\
\hline & $\begin{array}{l}\text { Benzalkonium } \\
\text { chloride }\end{array}$ & No activation & & \\
\hline \multirow[t]{12}{*}{ ERK } & Sensitisers & & & \multirow{12}{*}{$\begin{array}{l}\text { Aiba et al. (2003), Antonios et al. (2009), } \\
\text { Arrighi et al. (2001), Boisleve et al. (2005), } \\
\text { Bruchhausen et al. (2003), } \\
\text { Matos et al. (2005a, 2005b), } \\
\text { Miyazawa et al. (2008), Nukada et al. (2008), } \\
\text { Trompezinski et al. (2008) }\end{array}$} \\
\hline & Nickel & Activation & $\begin{array}{l}\text { Up-regulation of IL-6, IL-8, IL-1 } \beta \text {, TNF- } \alpha \text {, } \\
\text { CD83, CD86, CD54, CD40, CCR7 }\end{array}$ & \\
\hline & TNCB & Activation & & \\
\hline & DNCB & $\begin{array}{l}\text { Contradictory } \\
\text { results }\end{array}$ & & \\
\hline & $\mathrm{CoCl}_{2}$ & Activation & & \\
\hline & Thimerosal & Inhibition & & \\
\hline & DNFB & $\begin{array}{l}\text { Contradictory } \\
\text { results }\end{array}$ & & \\
\hline & $\mathrm{K}_{2} \mathrm{Cr}_{2} \mathrm{O}_{7}$ & No activation & & \\
\hline & Irritants & & & \\
\hline & SDS & No activation & & \\
\hline & $\begin{array}{l}\text { Benzalkonium } \\
\text { chloride }\end{array}$ & No activation & & \\
\hline & SLS & No activation & & \\
\hline \multirow[t]{11}{*}{ JNK } & Sensitisers & & & \multirow{11}{*}{$\begin{array}{l}\text { Aiba et al. (2003), Antonios et al. (2009, 2010), } \\
\text { Arrighi et al. (2001), Boisleve et al. (2004, 2005), } \\
\text { Trompezinski et al. (2008) }\end{array}$} \\
\hline & Nickel & $\begin{array}{l}\text { Contradictory } \\
\text { results }\end{array}$ & $\begin{array}{l}\text { Up-regulation on IL-6, IL-12, CD83, CD86, } \\
\text { CCR7, TNF- } \alpha\end{array}$ & \\
\hline & $\mathrm{CoCl}_{2}$ & Activation & & \\
\hline & DNCB & Activation & & \\
\hline & Thimerosal & Activation & & \\
\hline & DNFB & No activation & & \\
\hline & $\mathrm{K}_{2} \mathrm{Cr}_{2} \mathrm{O}_{7}$ & No activation & & \\
\hline & Irritants & & & \\
\hline & SDS & No activation & & \\
\hline & $\begin{array}{l}\text { Benzalkonium } \\
\text { chloride }\end{array}$ & No activation & & \\
\hline & SLS & No activation & & \\
\hline \multirow[t]{6}{*}{ p38 MAPK } & Sensitisers & & & Ade et al. (2007), Aiba et al. (2003), \\
\hline & Nickel & Activation & $\begin{array}{l}\text { Up-regulation of CD80, CD83, CD86, CD54, } \\
\text { CCR7, CD40, IL-8, IL-12, IL-6, IL-8, TNF- } \alpha\end{array}$ & $\begin{array}{l}\text { Antonios et al. (2009, 2010), Arrighi et al. (2001), } \\
\text { Boisleve et al. (2004, 2005), Bruchhausen et al. }\end{array}$ \\
\hline & DNFB & Activation & & (2003), Iijima et al. (2003), Matos et al. (2005a, \\
\hline & DNCB & Activation & & 2005b), Megherbi et al. (2009), \\
\hline & TNCB & Activation & & Mitjans et al. (2008, 2010), Miyazawa et al. (2008), \\
\hline & Thimerosal & Activation & & Nukada et al. (2008), Trompezinski et al. (2008) \\
\hline
\end{tabular}


Table 1 (continued)

\begin{tabular}{|c|c|c|c|c|}
\hline Signalling pathway & Chemical & $\begin{array}{l}\text { Type of } \\
\text { modulation }\end{array}$ & Phenotypic modification & References \\
\hline \multirow[t]{16}{*}{ p38 MAPK } & $\mathrm{CoCl}_{2}$ & Activation & & \\
\hline & Cinnamaldehyde & Activation & & \\
\hline & PPD & Activation & & \\
\hline & 2-aminophenol & Activation & & \\
\hline & Isoeugenol & Activation & & \\
\hline & Diethyl maleate & Activation & & \\
\hline & Citral & Activation & & \\
\hline & Imidazolidinyl urea & Activation & & \\
\hline & Penicillin G & Activation & & \\
\hline & $\mathrm{K}_{2} \mathrm{Cr}_{2} \mathrm{O}_{7}$ & No activation & & \\
\hline & Irritants & & & \\
\hline & SDS & No activation & & \\
\hline & $\begin{array}{l}\text { Benzalkonium } \\
\text { chloride }\end{array}$ & No activation & & \\
\hline & SLS & No activation & & \\
\hline & Propylene glycol & No activation & & \\
\hline & Lactic acid & No activation & & \\
\hline \multirow[t]{15}{*}{ Nrf2/ARE } & Sensitisers & & & Ade et al. (2009), Lewis et al. (2006), \\
\hline & Nickel & Activation & $\begin{array}{l}\text { Up-regulation of HMOX1 and NQO1 mRNA } \\
\text { expression }\end{array}$ & Megherbi et al. (2009) \\
\hline & Dinitrohalobenzenes & Activation & & \\
\hline & Cinnamaldehyde & & & \\
\hline & 7-hydroxycitronellal & Activation & & \\
\hline & 1,4-dihydroquinone & Activation & & \\
\hline & Lilial & Activation & & \\
\hline & p-Phenylenediamine & Activation & & \\
\hline & Penicillin & Activation & & \\
\hline & Irritants & & & \\
\hline & SDS & No activation & & \\
\hline & $\begin{array}{l}\text { Benzalkonium } \\
\text { chloride }\end{array}$ & No activation & & \\
\hline & Non-sensitizer & & & \\
\hline & Chlorobenzene & No activation & & \\
\hline & Nickel & No activation & & \\
\hline \multicolumn{5}{|l|}{ Redox imbalance } \\
\hline \multirow{12}{*}{ Cell surface thiols } & Sensitisers & & & Hirota et al. (2009), Kagatani et al. (2010), \\
\hline & DNCB & Changes & $\begin{array}{l}\text { Up-regulation of CD86, CD83, HLA-DR, IL-8, } \\
\text { MIP-1 } \beta \text {, down-regulation of aquaporin-3 }\end{array}$ & Suzuki et al. (2009) \\
\hline & Nickel & Changes & & \\
\hline & Dephencyprone & Changes & & \\
\hline & Formadehyde & Changes & & \\
\hline & Squaric acid & Changes & & \\
\hline & Dibutylester & Changes & & \\
\hline & Irritants & & & \\
\hline & $\begin{array}{l}\text { Benzalkonium } \\
\text { chloride }\end{array}$ & Changes & & \\
\hline & Tween 80 & Changes & & \\
\hline & SDS & No changes & & \\
\hline & Glycerol & No changes & & \\
\hline Protein oxidation & DNFB & & & Matos et al. (2005a, 2005b) \\
\hline \multirow{12}{*}{$\begin{array}{l}\text { Ratio reduced glutathione/ } \\
\text { oxidised glutathione or } \\
\text { glutathione depletion }\end{array}$} & Sensitisers & & & Mizuashi et al. (2005) \\
\hline & DNCB, DNFB, DNBB, & Reduction/depletion & Up-regulation of CD86 & Megherbi et al. (2009) \\
\hline & DNIB and DNBS & Reduction/depletion & & \\
\hline & Nickel & Reduction & & \\
\hline & $\mathrm{MnCl}_{2}$ & Reduction & & \\
\hline & Thimerosal & Reduction & & \\
\hline & Formaldehyde & $\begin{array}{l}\text { Reduction (in DC and } \\
\text { not in THP-1) }\end{array}$ & & \\
\hline & Penicillin & No modification & & \\
\hline & Irritants & & & \\
\hline & SDS & No modification & & \\
\hline & $\mathrm{BC}$ & No modification & & \\
\hline & $\mathrm{ZnCl}_{2}$ & No modification & & \\
\hline
\end{tabular}

oxazolone, DNFB, and PPD) activated this signalling pathway, which was in contrast to the effect observed for the irritants SDS and BC (unpublished data). Concerning the other MAPKs, ERK and JNK, the results from the literature are indeed sparse and contradictory (Table 1); these differences may be due to different DC cell models used in the experiments. In the FSDC cell line, JNK was indeed activated by all skin sensitisers tested (nickel, oxazolone, DNFB, and PPD) but not the irritants SDS and BC (unpublished data). More studies should be performed to evaluate the accuracy of JNK activation in the discrimination between sensitisers and irritants.

\section{Activation of Janus kinases (JAK)/STAT pathways}

Cytokines are critical coordinators of the immune system and in particular, the IL-12 family of cytokines (IL-12, IL-17, IL-23 and more recently, IL-35) is a key player in the regulation of T cell responses, 
which is orchestrated by the monocytes, macrophages and dendritic cells that produce the IL-12 family of cytokines in response to danger signals. These cytokines activate similar members of the JAK/STAT signalling pathway due to homology in their receptor components. Therefore, it would be reasonable that skin sensitisers, recognised by DC as danger signals, modulate the JAK/STAT pathway. Whether the JAK/STAT signalling pathway is directly activated by contact sensitisers in antigen-presenting cells was investigated in studies in which human monocytes and monocyte-derived DC were stimulated with the structurally unrelated contact sensitisers $\mathrm{MCI} / \mathrm{MI}$, thimerosal, TNCB and formaldehyde and the phosphorylation of the transcription factors STAT1, STAT3, STAT4, STAT5 and STAT6 was determined (Valk et al., 2002). In contrast to the positive controls performed with cytokines, hapten treatment did not stimulate a significant increase in STAT phosphorylation. These results showed that contact allergens do not directly activate common JAK/STAT pathways. However, the authors used short incubation periods $(15 \mathrm{~min})$ and it could be speculated that although contact allergens did not directly activate JAK/STAT, an effect on this signalling pathway may be observed with longer incubation times, which corresponds to an autocrine effect of cytokines released by DC in response to sensitisers. Recent studies also showed that $\mathrm{NiSO}_{4}$ induces STAT1 phosphorylation on serine and tyrosine residues that participate in $\mathrm{NiSO}_{4}$-induced IRF-1 activation in human dendritic cells (Antonios et al., 2010). However, the authors used longer incubation periods ( 2 to $4 \mathrm{~h}$ ). Therefore, experiments should be performed using cells stimulated with chemicals and analysed for JAK/STAT after long incubation times.

\section{Intracellular redox imbalance, changes in cell surface thiols and glutathione depletion}

The capacity of a small chemical compound to covalently bind to protein structures or to form stable complexes with proteins is one prerequisite to act as a hapten and a probable contact sensitiser. Putative reaction mechanisms of contact allergens with cell amino (lysine residues) and thiol (cysteine residues) groups have been proposed and implicated in the induction of hypersensitivity. Such direct interactions between haptens and thiol groups have been shown in mercury compounds (Santucci et al., 1998) and MCI/MI (Gruvberger and Bruze, 1998). The concept of protein binding was already used to develop an assay based on chemicals binding to cysteine-containing glutathione (Gerberick et al., 2004; Aptula et al., 2006). However, this approach has some limitations, namely for prohaptens and should be completed with biological assays.

Other studies reported that in monocytes and monocyte-derived dendritic cells, the increase in tyrosine phosphorylation induced by the contact sensitisers TNCB and $\mathrm{MCI} / \mathrm{MI}$ was dependent on its coupling to thiol groups (Becker et al., 2003). Indeed, tyrosine phosphorylation induced by strong sensitisers was completely prevented by cysteine but not lysine, suggesting a competitive mechanism between cysteine and the sulfhydryl groups of cell proteins. In these experiments, the authors studied the capacity of different antioxidants (ascorbic acid, alphatocopherol, pyrrolidine dithiocarbamate, $\mathrm{N}$-acetylcysteine and glutathione) to block the increase in tyrosine phosphorylation observed after human monocyte stimulation with strong contact sensitisers (Bruchhausen et al., 2003). The authors observed that only thiol antioxidants, namely $\mathrm{N}$-acetylcysteine and glutathione, blocked the increase in tyrosine phosphorylation induced by the sensitisers and concluded that the capacity of thiol antioxidants to block the binding of contact sensitisers to their cellular target structures could be the mechanism that prevents tyrosine phosphorylation. Accordingly, DNFB induced a significant increase in protein oxidation, as measured by the formation of carbonyl groups, while it had almost no effect on lipid peroxidation in the FSDC line. In addition, glutathione, but not vitamin $\mathrm{E}$, inhibited DNFB-induced p38 MAPK and ERK1/2 phosphorylation (Matos et al., 2005b). Whether sensitisers induce redox or oxidative stress in dendritic cells was investigated by measuring the ratio of the oxidised (GSSG) versus the reduced (GSH) form of cellular glutathione (Mizuashi et al., 2005); all of the sensitisers (nickel, formaldehyde, $\mathrm{DNCB}, \mathrm{MnCl}_{2}$, and thimerosal), but none of the non-sensitisers (SDS, BC, and $\mathrm{ZnCl}_{2}$ ), reduced the GSH/GSSG ratio, which was accompanied by p38 MAPK phosphorylation. The antioxidant N-acetyl-L-cysteine, which suppressed the reduction of the GSH/GSSG ratio, abrogated both the phosphorylation of p38 MAPK and the augmentation of CD86 expression, a common marker of the DC maturation induced by chemical sensitisers. The authors suggested that the GSH/GSSG imbalance plays a crucial role in triggering DC maturation by sensitisers. To identify the trigger for the intracellular redox imbalance induced by sensitisers, studies were performed to evaluate whether haptens directly or indirectly induce THP-1 maturation (Hirota et al., 2009). DNCB and nickel-induced related changes in cell surface thiols and phosphorylation of p38 MAPK, in a manner similar to that observed for an exogenous, cell-impermeable thiol oxidiser. The effect of sensitisers on the oxidation of cell surface thiols was further investigated in human monocyte-derived DC and THP1 (Suzuki et al., 2009; Kagatani et al., 2010); all sensitisers tested decreased cell surface thiols in parallel with phosphorylation of p38 MAPK and epicutaneous application of DNCB on mouse skin significantly decreased cell surface thiols of Langerhans cells in vivo. The results showed that oxidation of cell surface thiols is one of the triggers of dendritic cell maturation induced by haptens and may be useful for an in vitro sensitisation assay. A recent study showed that different dinitrohalobenzenes (DNCB, DNFB, DNBB, DNIB and DNBS) deplete intracellular glutathione to a similar extent in THP-1 cells (Megherbi et al., 2009). However and in contrast with the observations of other authors, GSH depletion via buthionine sulfoximine did not elicit cell maturation.

These in vitro approaches are corroborated with in vivo studies demonstrating that DNCB reacts with glutathione and depleted thiols in the viable epidermis following penetration through the stratum corneum (Pickard et al., 2009). Furthermore, glutathione metabolism in mice is preferentially enhanced in hapten-induced allergic contact dermatitis rather than in irritant contact dermatitis (Hirai et al., 1997).

Although using different approaches and different cell types, all these studies emphasise a crucial role for thiols in the process of DC maturation and in the subsequent development of ACD. In this context, changes in cell surface thiols induced by chemical sensitisers seem to be a promising output for integration into a testing strategy for skin sensitisation.

\section{Activation of the NF-kB transcription factor}

The NF-kB transcription factor plays an essential role in the optimal activation of the host immune system. Various immune responses in dendritic cells are positively regulated by NF-kB, such as the production of inflammatory mediators, cytokines/chemokines and the up-regulation of surface molecules (Kaisho and Tanaka, 2008). In addition, the NF-kB signalling pathway is reported to be involved in DC maturation (Rescigno et al., 1998; Arrighi et al., 2001; Aiba et al., 2003; Boisleve et al., 2005; Neves et al., 2009). Indeed some of the phenotypic and functional changes induced in DC by haptens are dependent upon the activation of NF-kB. Previous results in the FSDC line demonstrated that the sensitiser nickel activates the NF-kB and AP-1 transcription factors, as measured by the electrophoretic mobility shift assay (EMSA). Furthermore, DNFB differentially activates the various members of the NF-kB family (Cruz et al., 2002, 2004); three out of the five members, p50, p52 and RelB, were similarly activated upon DNFB stimulation with subsequent translocation of these subunits from the cytosol to the nucleus, although with different kinetics. In contrast, p65 expression was diminished in both the nucleus and the cytosol, suggesting the eventual activation of a non-canonical NF-kB pathway. None of the other skin sensitisers tested in the FSDC line (oxazolone, PPD and nickel) induced the degradation of IkB- $\alpha$ (unpublished data). In contrast with these results, nickel-induced IkB- $\alpha$ phosphorylation and NF-kB activation in 
human monocyte-derived DC (Aiba et al., 2003), but the inhibition of this pathway did not affect the induced phenotypic and functional changes. The effect of nickel on NF-kB in human monocyte-derived DC was specific, since no effect was observed in the presence of the irritants BC or SLS. More recently, it was also demonstrated in human dendritic cells that nickel, but not DNCB, activates the degradation of IkB- $\alpha$ leading to the binding of the NF-kB p65 subunit to specific DNA probes (Ade et al., 2007). NF-kB pathway inhibition using BAY 11-7085 prevents both CD40 and HLA-DR expression and cytokine production but only partially inhibits nickel-induced CD86 and CD83 expressions. These results showed that modifications of the DC phenotype induced by nickel, but not by DNCB, are probably the consequence of NF-kB activation. This work was recently extended to other metallic haptens, namely $\mathrm{CoCl}_{2}$ and $\mathrm{K}_{2} \mathrm{Cr}_{2} \mathrm{O}_{7}$ and the results demonstrated that nickel and $\mathrm{CoCl}_{2}$, but not $\mathrm{K}_{2} \mathrm{Cr}_{2} \mathrm{O}_{7}$, activate the NF-kB transcription factor in DC derived from $\mathrm{CD}_{3} 4^{+}$cord blood cells (Antonios et al., 2009). Furthermore, p38 MAPK, NF-kB and IRF-1 were involved in nickel-induced IL-12p40 production in human monocyte-derived DC (Antonios et al., 2010).

Taken together, these data indicate that although some sensitisers activate the NF-kB transcription factor and are probably responsible for some phenotypic modifications observed in DC, other sensitisers failed to activate this signalling pathway. For the group of sensitising chemicals that were unsuccessful in activating NF-kB, we can speculate that the phenotypical modifications observed are probably controlled by other signalling pathways and transcription factors, such as MAPKs and NRF2, or alternatively, a non-canonical pathway of NF-kB activation could be induced by allergens, as previously reported with other dendritic cell antigens (Gregory et al., 2008).

\section{Activation of the NRF2/ARE transcription factor signalling pathway}

A significant body of recent evidence indicates that the signalling pathway involving the repressor protein Keap1 (Kelch-like ECHassociated protein 1 ) and the transcription factor nuclear factorerythroid 2-related factor 2 ( $\mathrm{Nrf} 2$ ), which binds to the antioxidant response element (ARE) in the promoter region of many phase II detoxification genes, could be a potential marker of skin sensitisation hazards. Indeed, the Nrf2/ARE regulatory pathway is one of the most important cellular defence mechanisms against electrophilic stress, because Keap 1 may be covalently modified by electrophiles leading to the activation of ARE-dependent genes, such as thioredoxin, heme oxygenase (decycling) 1 (HMOX1), $\mathrm{NAD}(\mathrm{P}) \mathrm{H}$ dehydrogenase quinone 1 (NQO1) and quinone reductase, which are involved in the protection or neutralisation of chemical reactive species. Natsch and Emter (2008) pioneered this field and they evaluated whether this regulatory pathway could be used to develop a predictive cellular in vitro test for sensitisation. In this context, 96 different chemicals of known skin sensitisation potential were added to Hepa1C1C7 cells and the induction of the ARE-regulated quinone reductase $(\mathrm{QR})$ activity was determined. In parallel experiments, 102 chemicals were tested in the AREc32 reporter cell line, which contains an eightfold repeat of the ARE sequence upstream of a luciferase gene. Among the strong/extreme skin sensitisers, 14 out of 15 and 30 out of 34 moderate sensitisers induced the ARE-dependent luciferase activity and in many cases this response was paralleled by an induction of $Q R$ activity in Hepa1C1C7 cells. Sixty percent of the weak sensitisers also induced luciferase activity. Only 4 out of 30 tested non-sensitisers induced low levels of luciferase activity. Overall, a prediction accuracy of about $82 \%$ was achieved, which is only slightly lower than that obtained during the validation of the local lymph node assay. In another study, CD34-derived DC and the THP-1 myeloid cell line were treated with a panel of sensitisers, irritants and a non-sensitiser molecule (Ade et al., 2009). The expressions of HMOX1 and NQO1, which are dependent on Nrf2 activation, were measured using realtime PCR and cellular accumulation of Nrf2 was assessed by Western blot analysis. The increased expressions of HMOX1 and NQO1 mRNAs were observed at early time points in response to sensitisers (but not to irritants) and the accumulation of the Nrf2 protein was also observed only with chemical sensitisers. A significant inhibition of the expression of HMOX1 and NQO1 mRNAs and CD86 expression was found in DNCB-treated THP-1 cells preincubated with N-acetyl cysteine, a glutathione precursor. These results showed that electrophilic molecules, including sensitisers, activated the Keap1/Nrf2signalling pathway in dendritic cells and in the THP-1 cell line. Similarly, it was previously demonstrated that the skin sensitiser nickel activates the Nrf2 signalling pathway in human monocytic cells (Lewis et al., 2006) and our previous work demonstrated that thioredoxin, a protein encoded by a gene containing an ARE element in the promoter region, is involved in DC maturation (Francisco et al., 2010). The effect of dinitrohalobenzenes in Nrf2 was also tested in THP-1 cells, together with several other markers, namely for changes in CD54 levels, IL-8 release, p38 MAPK phosphorylation and NF-kB (Megherbi et al., 2009). Dinitrohalobenzenes failed to activate NF-kB but activated Nrf2 and depleted intracellular glutathione. Furthermore, a new in vitro method, which combined the measurement of glutathione depletion in a cell-free matrix with Keap1/Nrf2/ARE/ EpRE-mediated gene expression in human skin cells, showed promise for identifying chemicals and metals that induce skin sensitisation (McKim et al.). The Nrf2-Keap1-ARE regulatory pathway was recently proposed as a toxicity pathway specifically activated by cysteine-reactive compounds. Since electrophilicity is one of the most common features of skin sensitisers and is responsible for protein haptenation, it seems logical that electrophilic sensitisers activate the Nrf2/ARE signalling pathway. Therefore, this signalling pathway seems to be one of the most promising to sensor electrophilic skin sensitisers. However, electrophilicity is not the only mechanism by which chemicals can bind to proteins, since metallic sensitisers are not electrophiles and thiol sensitisers are nucleophiles. Furthermore, sensitisers, such as penicillin, that react with lysine residues appear to not activate this pathway and might trigger another unknown toxicity pathway (Natsch, 2010). Indeed, penicillin did not elicit maturation, Nrf2 activation or changes in GSH (Megherbi et al., 2009).

\section{Conclusion and future prospects}

Skin sensitisation is a complex biological phenomenon and it is now accepted that non-animal alternatives for the assessment of the sensitising potential of chemicals will require a combination of data from different endpoints, to truly replicate the sensitisation process in vitro. Among the favoured strategies are those based on the modifications induced by chemicals in DC or DC-like cell models. All of these modifications, both at the genomic and proteomic levels, are the consequence of a coordinated orchestration of different intracellular signalling pathways that are specifically triggered by skin sensitisers and not by irritants. From the literature, we can point out that, although different sensitisers stimulate different signal transduction pathways, the most promising signalling pathways for a platform of tests for skin sensitisation hazard are p38 MAPK, Nrf2/ARE and changes in cell surface thiols (Fig. 1). However, efforts are still required to further optimise existing methods and eventually identify more predictive signalling endpoints that have not yet been addressed. Indeed, it is reasonable to speculate that some of these predictive signalling endpoints may be downstream of the MAPKs signalling pathway, such as Elk-1, c-jun, JunD, activating transcription factor 2 (ATF-2) and cAMP response element-binding protein (CREB), because all are involved in co-stimulatory and cytokines/chemokine expression. Therefore, additional work is required to understand, in detail, the transduction pathways triggered by chemical sensitisers and to clarify the role of each pathway on the DC maturation/ activation process and, consequently, their involvement in the development of ACD. 


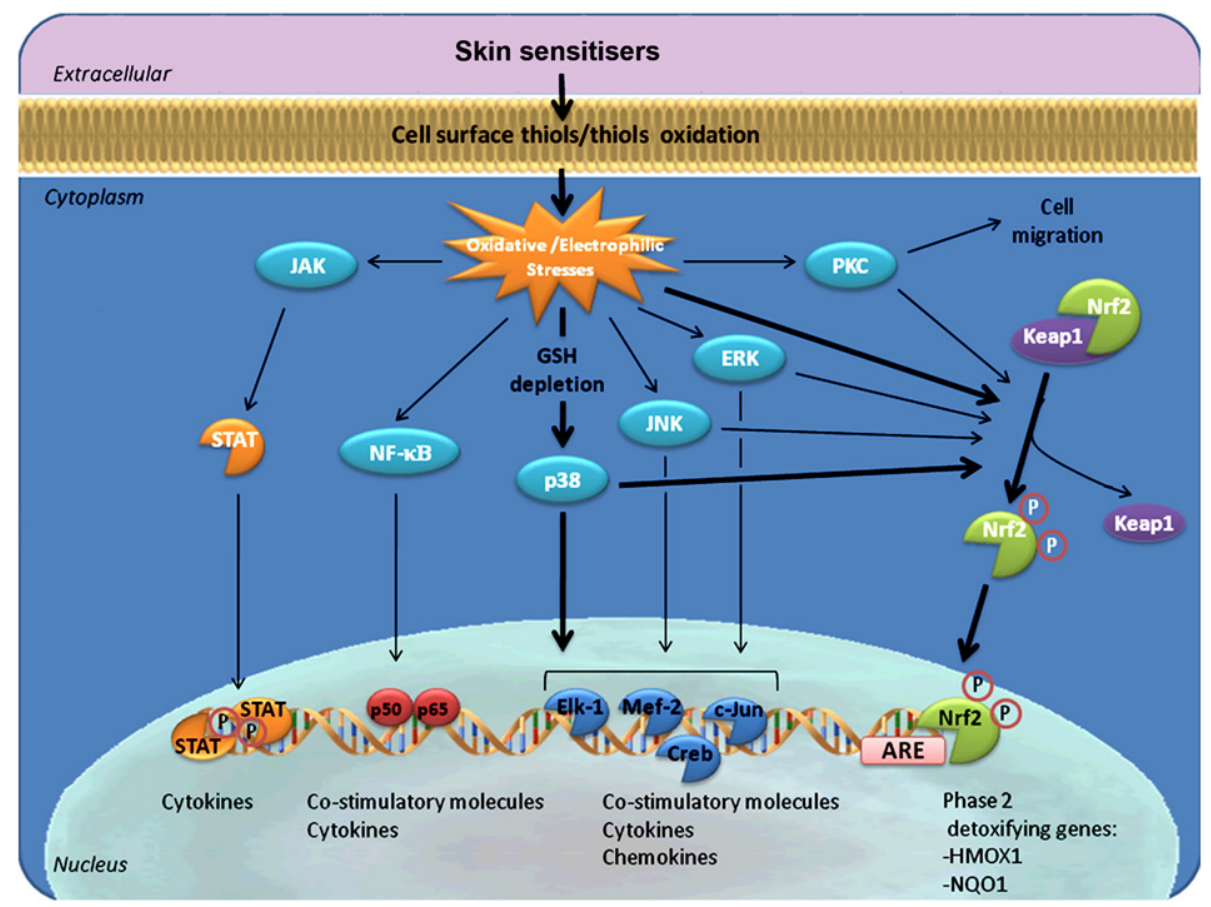

Fig. 1. Schematic view of the signalling pathways triggered by contact sensitisers in dendritic cells.

\section{Conflict of interest statement}

The authors declare that there are no conflicts of interest.

\section{Acknowledgments}

This review was supported by LIERAC (Ales Groupe), Fundação para a Ciência e Tecnologia (FCT), Fundo Comunitário Europeu (FEDER) and Programa Operacional Temático Factores de Competitividade (COMPETE) (Grant number PTDC/SAU-OSM/099762/2008 and Bruno Neves fellowship number SFRH/BD/30563/2006).

We thank Dr. G. Girolomoni (Department of Biomedical and Surgical Science, Section of Dermatology and Venereology, University of Verona, Italy) for the kind gift of the foetal skin-derived dendritic cell line (FSDC).

\section{References}

Ade, N., Antonios, D., Kerdine-Romer, S., Boisleve, F., Rousset, F., Pallardy, M., 2007. NFkappaB plays a major role in the maturation of human dendritic cells induced by NiSO(4) but not by DNCB. Toxicol. Sci. 99, 488-501.

Ade, N., Leon, F., Pallardy, M., Peiffer, J.L., Kerdine-Romer, S., Tissier, M.H., Bonnet, P.A., Fabre, I., Ourlin, J.C., 2009. HMOX1 and NQO1 genes are upregulated in response to contact sensitizers in dendritic cells and THP-1 cell line: role of the Keap1/Nrf2 pathway. Toxicol. Sci. 107, 451-460.

Aiba, S., Manome, H., Nakagawa, S., Mollah, Z.U., Mizuashi, M., Ohtani, T., Yoshino, Y., Tagami, H., 2003. p38 Mitogen-activated protein kinase and extracellular signalregulated kinases play distinct roles in the activation of dendritic cells by two representative haptens, $\mathrm{NiCl} 2$ and 2, 4-dinitrochlorobenzene. J. Invest. Dermatol. 120, 390-399.

Antonios, D., Ade, N., Kerdine-Romer, S., Assaf-Vandecasteele, H., Larange, A., Azouri, H., Pallardy, M., 2009. Metallic haptens induce differential phenotype of human dendritic cells through activation of mitogen-activated protein kinase and NFkappaB pathways. Toxicol. In Vitro 23, 227-234.

Antonios, D., Rousseau, P., Larange, A., Kerdine-Romer, S., Pallardy, M., 2010. Mechanisms of IL-12 synthesis by human dendritic cells treated with the chemical sensitizer $\mathrm{NiSO}(4)$. J. Immunol. 185, 89-98.

Aptula, A.O., Patlewicz, G., Roberts, D.W., Schultz, T.W., 2006. Non-enzymatic glutathione reactivity and in vitro toxicity: a non-animal approach to skin sensitization. Toxicol. In Vitro 20, 239-247.

Arrighi, J.F., Rebsamen, M., Rousset, F., Kindler, V., Hauser, C., 2001. A critical role for p38 mitogen-activated protein kinase in the maturation of human blood-derived dendritic cells induced by lipopolysaccharide, TNF-alpha, and contact sensitizers. J. Immunol. 166, 3837-3845.
Basketter, D.A., Evans, P., Fielder, R.J., Gerberick, G.F., Dearman, R.J., Kimber, I., 2002 Local lymph node assay - validation, conduct and use in practice. Food Chem. Toxicol. 40, 593-598.

Becker, D., Valk, E., Zahn, S., Brand, P., Knop, J., 2003. Coupling of contact sensitizers to thiol groups is a key event for the activation of monocytes and monocyte-derived dendritic cells. J. Invest. Dermatol. 120, 233-238.

Boisleve, F., Kerdine-Romer, S., Rougier-Larzat, N., Pallardy, M., 2004. Nickel and DNCB induce CCR7 expression on human dendritic cells through different signalling pathways: role of TNF-alpha and MAPK. J. Invest. Dermatol. 123, 494-502.

Boisleve, F., Kerdine-Romer, S., Pallardy, M., 2005. Implication of the MAPK pathways in the maturation of human dendritic cells induced by nickel and TNF-alpha. Toxicology 206, 233-244.

Bruchhausen, S., Zahn, S., Valk, E., Knop, J., Becker, D., 2003. Thiol antioxidants block the activation of antigen-presenting cells by contact sensitizers. J. Invest. Dermatol. $121,1039-1044$.

Cruz, M.T., Duarte, C.B., Goncalo, M., Figueiredo, A., Carvalho, A.P., Lopes, M.C., 2002 Differential activation of nuclear factor kappa B subunits in a skin dendritic cell line in response to the strong sensitizer 2, 4-dinitrofluorobenzene. Arch. Dermatol. Res. 294, 419-425.

Cruz, M.T., Goncalo, M., Figueiredo, A., Carvalho, A.P., Duarte, C.B., Lopes, M.C., 2004 Contact sensitizer nickel sulfate activates the transcription factors NF-kB and AP-1 and increases the expression of nitric oxide synthase in a skin dendritic cell line. Exp. Dermatol. 13, 18-26.

dos Santos, G.G., Reinders, J., Ouwehand, K., Rustemeyer, T., Scheper, R.J., Gibbs, S., 2009 Progress on the development of human in vitro dendritic cell based assays for assessment of the sensitizing potential of a compound. Toxicol. Appl. Pharmacol 236, 372-382.

EC, 2009. Regulation No 1223/2009 of the European Parliament and of the Council of 30 November 2009 on cosmetic products. Off. J. Eur. Union L 342/59.

EU, 2003. Directive 2003/15/EC of the European Parliament and of the Council of 27 February 2003 amending Council Directive 76/768/EEC on the approximation of the laws of the Member States relating to cosmetic products. Off. J. Eur. Union L66 26-35.

Francisco, V., Neves, B.M., Cruz, M.T., Goncalo, M., Figueiredo, A., Duarte, C.B., Lopes, M C., 2010. Effect of lipopolysaccharide, skin sensitizers and irritants on thioredoxin-1 expression in dendritic cells: relevance of different signalling pathways. Arch. Dermatol. Res. 302, 271-282.

Gerberick, G.F., Vassallo, J.D., Bailey, R.E., Chaney, J.G., Morrall, S.W., Lepoittevin, J.P., 2004. Development of a peptide reactivity assay for screening contact allergens. Toxicol. Sci. 81, 332-343.

Girolomoni, G., Lutz, M.B., Pastore, S., Assmann, C.U., Cavani, A., Ricciardi-Castagnoli, P., 1995. Establishment of a cell line with features of early dendritic cell precursors from fetal mouse skin. Eur. J. Immunol. 25, 2163-2169.

Gregory, D.J., Godbout, M., Contreras, I., Forget, G., Olivier, M., 2008. A novel form of NFkappaB is induced by Leishmania infection: involvement in macrophage gene expression. Eur. J. Immunol. 38, 1071-1081.

Gruvberger, B., Bruze, M., 1998. Can glutathione-containing emollients inactivate methylchloroisothiazolinone/methylisothiazolinone? Contact Dermat. 38 261-265. 
Halliday, G.M., Lucas, A.D., 1993. Protein kinase C transduces the signal for Langerhans' cell migration from the epidermis. Immunology 79, 621-626.

Hirai, A., Minamiyama, Y., Hamada, T., Ishii, M., Inoue, M., 1997. Glutathione metabolism in mice is enhanced more with hapten-induced allergic contact dermatitis than with irritant contact dermatitis. J. Invest. Dermatol. 109, 314-318.

Hirota, M., Suzuki, M., Hagino, S., Kagatani, S., Sasaki, Y., Aiba, S., Itagaki, H., 2009. Modification of cell-surface thiols elicits activation of human monocytic cell line THP-1: possible involvement in effect of haptens 2, 4-dinitrochlorobenzene and nickel sulfate. J. Toxicol. Sci. 34, 139-150.

Iijima, N., Yanagawa, Y., Onoe, K., 2003. Role of early- or late-phase activation of p38 mitogen-activated protein kinase induced by tumour necrosis factor-alpha or 2, 4 dinitrochlorobenzene during maturation of murine dendritic cells. Immunology $110,322-328$.

Kagatani, S., Sasaki, Y., Hirota, M., Mizuashi, M., Suzuki, M., Ohtani, T., Itagaki, H., Aiba, S. 2010. Oxidation of cell surface thiol groups by contact sensitizers triggers the maturation of dendritic cells. J. Invest. Dermatol. 130, 175-183.

Kaisho, T., Tanaka, T., 2008. Turning NF-kappaB and IRFs on and off in DC. Trends Immunol. 29, 329-336.

Koeper, L.M., Schulz, A., Ahr, H.J., Vohr, H.W., 2007. In vitro differentiation of skin sensitizers by cell signaling pathways. Toxicology 242, 144-152.

Kuhn, U., Brand, P., Willemsen, J., Jonuleit, H., Enk, A.H., van Brandwijk-Petershans, R. Saloga, J., Knop, J., Becker, D., 1998. Induction of tyrosine phosphorylation in human MHC class II-positive antigen-presenting cells by stimulation with contact sensitizers. J. Immunol. 160, 667-673.

Lewis, J.B., Messer, R.L., McCloud, V.V., Lockwood, P.E., Hsu, S.D., Wataha, J.C., 2006. Ni (II) activates the Nrf2 signaling pathway in human monocytic cells. Biomaterials 27, 5348-5356.

Matos, T.J., Duarte, C.B., Goncalo, M., Lopes, M.C., 2005a. DNFB activates MAPKs and upregulates CD40 in skin-derived dendritic cells. J. Dermatol. Sci. 39, 113-123.

Matos, T.J., Duarte, C.B., Goncalo, M., Lopes, M.C., 2005b. Role of oxidative stress in ERK and $\mathrm{p} 38$ MAPK activation induced by the chemical sensitizer DNFB in a fetal skin dendritic cell line. Immunol. Cell Biol. 83, 607-614.

McKim, J.M., Keller, D.J., Gorski, J.R., 2010. A new in vitro method for identifying chemical sensitizers combining peptide binding with ARE/EpRE-mediated gene expression in human skin cells. Cutan. Ocul. Toxicol. 29, 171-192.

Megherbi, R., Kiorpelidou, E., Foster, B., Rowe, C., Naisbitt, D.J., Goldring, C.E., Park, B.K. 2009. Role of protein haptenation in triggering maturation events in the dendritic cell surrogate cell line THP-1. Toxicol. Appl. Pharmacol. 238, 120-132.

Mitjans, M., Viviani, B., Lucchi, L., Galli, C.L., Marinovich, M., Corsini, E., 2008. Role of p38 MAPK in the selective release of IL- 8 induced by chemical allergen in naive THp-1 cells. Toxicol. In Vitro 22, 386-395.

Mitjans, M. Galbiati, V., Lucchi, L., Viviani, B., Marinovich, M., Galli, C.L., Corsini, E., 2010. Use of IL-8 release and p38 MAPK activation in THP-1 cells to identify allergens and to assess their potency in vitro. Toxicol. In Vitro.

Miyazawa, M., Ito, Y., Kosaka, N., Nukada, Y., Sakaguchi, H., Suzuki, H., Nishiyama, N., 2008. Role of MAPK signaling pathway in the activation of dendritic type cell line, THP-1, induced by DNCB and NiSO4. J. Toxicol. Sci. 33, 51-59.

Mizuashi, M., Ohtani, T., Nakagawa, S., Aiba, S., 2005. Redox imbalance induced by contact sensitizers triggers the maturation of dendritic cells. J. Invest. Dermatol. 124, 579-586.

NATIONAL RESEARCH COUNCIL (NRC), 2007. Toxicity Testing in the 21st Century: A Vision and A Strategy. National Academy Press, Washington, DC.
Natsch, A., 2010. The Nrf2-Keap1-ARE toxicity pathway as a cellular sensor for skin sensitizers-functional relevance and a hypothesis on innate reactions to skin sensitizers. Toxicol. Sci. 113, 284-292.

Natsch, A., Emter, R., 2008. Skin sensitizers induce antioxidant response element dependent genes: application to the in vitro testing of the sensitization potential of chemicals. Toxicol. Sci. 102, 110-119.

Neisius, U., Brand, P., Plochmann, S., Saloga, J., Knop, J., Becker, D., 1999. Detection of increased tyrosine phosphorylation in murine Langerhans cells after stimulation with contact sensitizers. Arch. Dermatol. Res. 291, 22-27.

Neves, B.M., Cruz, M.T., Francisco, V., Goncalo, M., Figueiredo, A., Duarte, C.B., Lopes, M. C., 2008. Differential modulation of CXCR4 and CD40 protein levels by skin sensitizers and irritants in the FSDC cell line. Toxicol. Lett. 177, 74-82.

Neves, B.M., Cruz, M.T., Francisco, V., Garcia-Rodriguez, C., Silvestre, R., Cordeiro-daSilva, A., Dinis, A.M., Batista, M.T., Duarte, C.B., Lopes, M.C., 2009. Differential roles of PI3-Kinase, MAPKs and NF-kappaB on the manipulation of dendritic cell T(h)1/T(h) 2 cytokine/chemokine polarizing profile. Mol. Immunol. 46, 2481-2492.

Nukada, Y., Miyazawa, M., Kosaka, N., Ito, Y., Sakaguchi, H., Nishiyama, N., 2008. Production of IL-8 in THP-1 cells following contact allergen stimulation via mitogen-activated protein kinase activation or tumor necrosis factor-alpha production. J. Toxicol. Sci. 33, 175-185.

Pickard, C., Louafi, F., McGuire, C., Lowings, K., Kumar, P., Cooper, H., Dearman, R.J., Cumberbatch, M. Kimber, I. Healy, E, Friedmann, P.S., 2009. The cutaneous biochemical redox barrier: a component of the innate immune defenses against sensitization by highly reactive environmental xenobiotics. J. Immunol. 183, 7576-7584.

Rescigno, M., Martino, M., Sutherland, C.L., Gold, M.R., Ricciardi-Castagnoli, P., 1998. Dendritic cell survival and maturation are regulated by different signaling pathways. J. Exp. Med. 188, 2175-2180.

Ryan, C.A., Kimber I., Basketter, D.A., Pallardy, M., Gildea, L.A., Gerberick, G.F. 2007. Dendritic cells and skin sensitization: biological roles and uses in hazard identification. Toxicol. Appl. Pharmacol. 221, 384-394.

Santucci, B., Cannistraci, C., Cristaudo, A., Camera, E., Picardo, M., 1998. Thimerosal positivities: the role of $\mathrm{SH}$ groups and divalent ions. Contact Dermat 39, 123-126.

Staquet, M.J., Piccardi, N., Piccirilli, A., Vincent, C., Schmitt, D., Msika, P., 2004. Novel protein kinase $C$ and matrix metalloproteinase inhibitors of vegetable origin as potential modulators of Langerhans cell migration following hapten-induced sensitization. Int. Arch. Allergy Immunol. 133, 348-356.

Suzuki, M., Hirota, M., Hagino, S., Itagaki, H., Aiba, S., 2009. Evaluation of changes of cellsurface thiols as a new biomarker for in vitro sensitization test. Toxicol. In Vitro 23, 687-696.

Thyssen, J.P., Linneberg, A., Menné, T., Johansen, J.D., 2007. The epidemiology of contact allergy in the general population-prevalence and main findings. Contact Dermat. 57, 287-299.

Trompezinski, S., Migdal, C., Tailhardat, M., Le Varlet, B., Courtellemont, P., Haftek, M., Serres, M., 2008. Characterization of early events involved in human dendritic cell maturation induced by sensitizers: cross talk between MAPK signalling pathways. Toxicol. Appl. Pharmacol. 230, 397-406.

Valk, E., Zahn, S., Knop, J., Becker, D., 2002. JAK/STAT pathways are not involved in the direct activation of antigen-presenting cells by contact sensitizers. Arch. Dermatol. Res. 294, 163-167.

Vital, A.L., Goncalo, M., Cruz, M.T., Figueiredo, A., Duarte, C.B., Celeste Lopes, M., 2004. The sensitizers nickel sulfate and 2, 4-dinitrofluorobenzene increase CD40 and IL12 receptor expression in a fetal skin dendritic cell line. Biosci. Rep. 24, 191-202. 